REVIEW

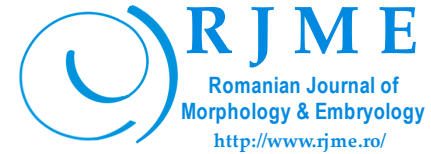

\title{
Genetic aspects in schizophrenia. Receptoral theories. Metabolic theories
}

\author{
SimONa CORINA TRIFU' ${ }^{1)}$, ANCA VLĂdUTII ${ }^{2)}$, ANTONiA IOANA TRIFU ${ }^{3)}$ \\ 1) Department of Neurosciences, Carol Davila University of Medicine and Pharmacy, Bucharest, Romania \\ 2) Department of Psychology, Faculty of Psychology and Educational Sciences, University of Bucharest, \\ Romania \\ 3)Department of General Medicine, Medical Military Institute, Bucharest, Romania
}

\begin{abstract}
Ties between schizophrenia (SCZ) and genetics are undeniably significant issue prone to be discussed in the nowadays psychology. Recent research on this domain focuses more on specific genes and heredity (specifically monozygotic pairs of twins) for diagnosing SCZ, than on environmental influences. SCZ is considered a multifactorial disease, thought to convert from a merger of risk and biological genes and environmental factors that could alter and reshape the trajectory of brain development. On this regard, this review sums up recent and innovative methods of distinguishing schizophrenic features from other mental illnesses in patients, based on chromosomal and genes changes. The term "reverse genetics" is no longer up to date, being replaced with "genome scanning" and "positional cloning". For many researchers, genome scanning is continuing the reverse of the sensible strategy for detecting various important biological disorders, which may start from the discovery of a protein or any other molecule involved in a biological process, being followed by its gene cloning. Genes being discovered in this manner could become candidate genes for the disease. However, genome scanning occurs through testing each chromosomal segment (or mitochondrial genome) for the counter transmission of the disease.
\end{abstract}

Keywords: schizophrenia, genetics, genes, hereditary.

\section{$\square$ Introduction}

Schizophrenia (SCZ) diagnosis is based on the presence of positive symptoms, negative symptoms and cognitive impairments. The positive symptoms are mainly centered on delusions and hallucinations combined with disorganization of speech, grossly disorganization. The negative symptoms can be separated in two subcategories: avolition/ apathy and diminished expression [1]. A number of symptoms contribute to the diagnosis and they start from derealization, unusual affect, cognitive deficits and can reach hostility, aggression. SCZ is considered one of the most disastrous disorders from economical point of view [2]. On this regard, it is added that personal (self-stigma), experienced or perceived stigma among patients suffering from SCZ plays a huge role affecting their self-esteem, social interactions and could lead to increasing level of depression and anxiety [3]. Moreover, due to social desirability, respondents suffering from SCZ could mislead the test results [4]. Usually, a negative outcome for these patients is about $40 \%$ and only approximately $16 \%$ can recover partially their functionality at the social level, and we see a reduction of the symptoms. $\mathrm{SCZ}$ has a prevalence approaching $1 \%$ at the international level with an incidence of 1.5 per 10000 people [5].

Starting with Diagnostic and Statistical Manual of Mental Disorders, $5^{\text {th }}$ edition (DSM-5), due to limited diagnostic stability, low reliability and decreased validity, some subtypes of SCZ have been eliminated and the focus has been placed on the severity of symptoms and the psychopathological dimension.
Large studies have been made to determine the anomalies in the thickness of cortical grey matter in SCZ and has been revealed that, in this case, the almost entire cortex is affected (the primary visual cortex did not show any modifications). Moreover, studying the brain structural abnormalities and the hippocampal volume deficits, higher rates of reduction of the hippocampus, ventricles, thalamus, amygdala and nucleus accumbens have been observes together with significant structural abnormalities. Considering the microstructure of white matter, fractional anisotropy is lower in the full skeleton and in almost all individual regions [6].

\section{ㅁ Receptoral theories in SCZ}

Modern antipsychotics have been achieved starting from the idea of maximizing the incisive effects, regarding the "attack" on psychotic productivity (action found on D2 receptors), alongside with improving the negative phenomenology (action taken particularly on D3 receptors and in subsidiary on D4 receptors, whose function is less known), minimizing adverse reactions. Many contemporary antipsychotics resulted from stroking one chain (see Olanzapine derives from Clozapine by stroking one side chain), the aim being the annulment of the effects which "kick" the corporeality (prevalently the spinal cord agranulocytosis).

Knowing that patients with SCZ have large difficulties regarding the working memory, the stimulation of D1 receptors (that are dopamine receptors) present in dorsolateral prefrontal cortex can be associated with the cognitive

This is an open-access article distributed under the terms of a Creative Commons Attribution-NonCommercial-ShareAlike 4.0 International Public License, which permits unrestricted use, adaptation, distribution and reproduction in any medium, non-commercially, provided the new creations are licensed under identical terms as the original work and the original work is properly cited. 
impairments, that means an increased sensitivity to antagonists and by desensitizing of the receptors, a long-term positive effect can be achieved [7].

Likewise, one of the modern psychiatry's goals would be developing new molecules, which would mainly cause an impact not only on dopamine neurons, found in the dorsolateral prefrontal cortex, but also on hippocampal neurons. The aim being to address the disorganization's dimension of the SCZ thinking phenomenology (tangentiality, circumstantiality, weakening of the logical associations, removing the significance from the signified, the construction of syllogisms, the reversal between cause and effect, deficit of mentalization). The currently used medication in this area has higher remarkable results regarding the productive psychotic area, but shows lower performance in the disorganization areas of thinking, speech and behavior.

\section{a Metabolic theories in SCZ}

$\mathrm{SCZ}$ is considered a severe disorder in what regards the psychiatric spectrum, for which basic causes are not completely understood. The brain, for maintaining its functions, has a primary source of energy depended on the oxidative metabolism, and in many studies, as part of the SCZ pathogenesis, there has been suggested a disturbance of its energy metabolism. These studies revealed that the glucose's oxidative metabolism anomalies could contribute to one's sensibility to develop psychosis. Indeed, there is compelling evidence that patients who suffer from SCZ have deteriorated carbohydrate metabolism, with lower metabolic rates and reduction in blood flow, found in the frontal cortex, which is exposed during cognitive tasks [8].

Damaged oxidative metabolism mainly suggests mitochondrial dysfunction, because mitochondria are primary sources of aerobic energy for neural function, by oxidative phosphorylation. Moreover, there is evidence that mitochondria play a major role in cellular processes, which are disturbed in SCZ, in synaptic transmission and in oxidative stress. It has also been reported the comorbidity between mitochondrial diseases and general neuropsychiatric symptomatology.

\section{ㅁ Morphological modifications}

Studying the subcortical brain structures, researchers have established various brain volumes modifications, structural abnormalities, highlighted decreases of the hippocampal volumes (both right and left) and increases of pallidum volumes (more significant on the left one compared with the right one), inferior parietal volume. They tried to highlight also the volume differences for the patients that had an intelligence quotient (IQ) not modified by the disease and the ones with a deteriorated IQ. The comparison shown that a non-functional IQ has lower subcortical structure volumes than the ones with preserved IQ. The same study has confirmed the findings from other studies: the total volume of the brain is lower for patient suffering of SCZ and the cortical thickness is also lower. Interesting is also that they show the cortical thickness is lower on the patients with a deteriorated IQ comparing with the ones with an IQ not modified.
The analysis of hyperconductivity between cortical areas and thalamus has proved a significant hyperconductivity in almost all cortical areas [9]. Nevertheless, these findings are not specific features of SCZ but they can be a step forward in relating brain structures modifications with IQ level of the patient. The same study highlighted an evolution perspective for the patients with SCZ, mentioning that a smaller right pars triangularis gyrus volume can identify a higher deterioration of cognitive functions of the patient.

We should not forget that functional magnetic resonance imaging (fMRI), as a measure of changes in the blood flow of the brain, used in these investigations is influenced by the age of the patient due to changes in the bloodoxygen-level-dependent (BOLD) signals as the ageing of neurovascular brain system. The age influences also the gray matter that decreases linearly with a percentage between $9-12 \%$, according to age. Even more, the morphological structures can also be influenced by genetic factors, independent of the status of the patient at a certain time, and also, we should consider the cognitive development and personality traits of the patient. The findings aforesaid of the study can be taken as they highlight the modifications of brain structures and hyperconductivity without considering the changes in values, even as percentage, as specific findings for SCZ.

In the same time, the pathology of white matter in SCZ research has gain more a more importance due to a more than 10 years old technology called diffusion tensor imaging (DTI), based on the diffusion of water in biological tissue (under MRI environment). The technology can identify changes in tissue microstructures of the brain and they can be used in mental disorders as SCZ. Even if this technology is error sensitive to artifacts of the images, thermal noise and physiological changes, it can highlight the tracts of white matter together with its anisotropy.

The researchers established that an increase of interstitial white matter neurons (IWMNs) directly under the cortical regions (dorsolateral prefrontal cortex, orbitofrontal cortex, inferior parietal cortex, cingulate white matter) is implicated in the pathology of SCZ [10]. Studying several demonstrated mechanism of action based on an injury/inflammation, like an in utero infection that leads the impossibility of the subplate neurons to migrate into cortical layer and remain in the white matter, resulting an increase of IWMNs, or considering an injury of the brain (associated with an inflammation) that leads to a reaction of the subependymal zone, producing new neurons that fail to pass through white matter and remain captured, the SCZ is related to an abnormal migration of IWMNs that remain hooked in the white matter. We should not forget that a large number of IWMNs are gamma-aminobutyric acid (GABA)ergic and some of GABAergic neurons that do not make a full migration in the cortex remain captive in white matter. In this way, glutamate decarboxylase isoform weight $67 \mathrm{kDa}$ (GAD67) encoded by GADl gene, is one of the key elements/ enzymes in inhibiting effect of GABA; in this way, low values of GAD67 in dorsolateral prefrontal cortex are measured in patients with SCZ. 
One category of fast-spiking GABAergic neurons is parvalbumin interneurons. They control the inhibitory process of cortical and subcortical circuits, fact that demonstrate their implication in the symptoms of SCZ. Due to their fast-spiking oscillation, they are directly involved in cognitive processes of the SCZ patients. Several researchers have studied the density of parvalbumin interneurons in prefrontal cortex and the parvalbumin messenger ribonucleic acid (mRNA) levels using different methods of investigation. The parameters and the measured values are clearly sensitive to the methodology (e.g., tissue fixation in paraffin or formalin), the co-morbidity of the patient (e.g., alcohol consumption), neither one of the studies have considered the genetic inheritance of the patient. The studies have concluded that there is a reduced neuronal density of parvalbumin interneurons in the frontal cortex without considering as statistically significant the modification of mRNA levels [11].

Using the same DTI technique, the researches has established that in SCZ a low fractional anisotropy can be distinguished. They concluded that this can be the result also of a myelination deficit in all brain areas. It can be due to an oligodendrocyte dysfunction affecting the propagation of impulses through nerve and from that to cognitive dysfunctions [12]. A decreased number of oligodendrocytes in the anterior and posterior left hippocampus corresponding to the cornu Ammonis 4 (CA4) region has been reported. In this way, the regenerative recovery process is affected due to the failure of maturation of the cells. Interesting is also that the number of oligodendrocytes is not influenced by the dose of antipsychotic medication. Myelin basic protein gene decreased expression discovered to the patients with SCZ leads to the migrational deficits of the pre-alpha-cell clusters in the entorhinal cortex. From all these facts, a deficit in neural development seems to be at the origin of SCZ.

\section{$\neg$ Genetic debates in SCZ}

Consistent within the previously mentioned information, found in "Introduction" section, Gonçalves et al. [8] discovered that genetic risk factors of SCZ have not been understood entirely. Several studies highlight that mitochondrial dysfunction has a major role, but extensive studies of covering on this topic are absent.

SCZ has a powerful genetic basis, containing studies which argue for an estimated heredity of $80 \%$. However, hardly any studies focus especially on discovering mitochondrial loci being associated with SCZ. There are few evidences suggesting that mitochondrial genes play a role in SCZ [13]. For instance, the latest results obtained by Psychiatric Genomics Consortium (PGC) are found in a phase 2 study ( $P G C$-SCZ2), an association study in genomes of several genes which are involved in the transmission of SCZ [genome-wide association study (GWAS)]. The study included the experimental group having 35476 patients and the control group containing 46839 subjects. This represents the largest data set, so far used for the genetic association studies, regarding SCZ. There has been reported evidence with reference to 22 nuclear-encoded mitochondrial genes. In addition, a larger study, conducted as a next step, on 9379 experimental patients and 7736 control subjects, underlined that transmission paths, being associated with the mitochondria, did not show any significant connection with the disease.

It has been postulated the hypothesis according to which nuclear encoded mitochondrial genetic variations influence the sensitivity to SCZ. There have been conducted analyses on genes and sets of genes using cursory association results offered by $P G C$ in the "Schizophrenia Phase 2 ( $P G C$-SCZ2)" study. It has been used MAGMA method on three sets of nuclear encoded mitochondrial genes: oxidative phosphorylation genes, other nuclear encoded mitochondrial genes and genes being involved in mitochondrial-nuclear cross. Also, based on the iPSYCH SCZ sample, another study made on 2290 disease cases and 21621 controls has tried to obtain the same results.

In the $P G C$-SCZ2 sample, 1186 mitochondrial genes were under analysis, 159 of them having $p$-values of 0.05 and 19 remaining significant after performing test corrections. Another analysis combines the PGC-SCZ2 and iPSYCH samples and included 818 genes, which led to the discovery of 104 significant genes and nine forefront genes, suggesting that nuclear-encoded mitochondrial genes have a polygenic model.

Furthermore, the $P G C$-SCZ2 study identified a direct interaction between 14 mitochondrial genes and 158 genes at risk of SCZ by conducting an in silico protein analysis (permutation test, $p=0.02$ ). Moreover, the signaling of aldosterone in epithelial cells and dysfunctions in mitochondrial conducting ways appeared to be over-represented in this mitochondrial risk gene network and SCZ.

Vassos et al. [14] made a reference in his study to the general context of the polygenic risk scores (PRSs), which have successfully summed up the effects in genomes of the genetic variants having significant prediction power in SCZ. Furthermore, on a number of patients having first-episode psychosis (FEP), there has been estimated the power of discrimination of PRSs regarding: control group subjects, subjects who later on will develop other forms of psychosis and subjects who will develop SCZ in the future. The sample, containing 445 cases of first episode of acute psychosis and 265 controls, was genotyped on Human Core Exome BeadChip from Illumina, having an increase of 828 control subjects borne in Africa, genotyped on the Multi-Ethnic Genotypic Array (MEGA) from Illumina. In order to determine the PRSs, there have been used the most recent results from meta-analyses regarding SCZ, found in $P G C$. There has been examined the association of PRSs with the control cases status, namely the SCZ and the other forms of psychosis status. This procedure was distinctly performed on subjects of European versus African origin. Alongside the FEP subjects' sample, there has been used another group of subjects, formed by 248 patients, deemed having chronic psychosis.

PRSs had higher discriminatory power regarding the control cases (healthy subjects) of people who had European ancestors, who developed a FEP $(9.4 \%$ of the explained variation, $\left.p<10^{-6}\right)$, but lower discriminatory power for individuals who had African ancestors $\left(R^{2}=1.1 \%, p=0.004\right)$. Moreover, PRSs has distinguished between subjects of European origin, who developed the diagnosis of SCZ and subjects who later on developed other forms of psychosis 
$\left(R^{2}=9.2 \%, p=0.002\right)$. PRSs were a strong predictor for the health status (control group subjects) of a European sample of patients having FEP, though an extensive proportion of the sample, at the moment of the evaluation, did not have an established diagnosis of SCZ. Furthermore, comparing the PRSs between the subjects that developed SCZ and those who did not, significant differences have been identified but without sufficient clinic utility.

\section{$\neg$ Stress - diathesis model in the vision of Paul Tooney}

Tooney's article starts from the idea that SCZ is described as a multifactorial disease that can be the result of a combination of risk genes and environmental factors, which changes the brain's normal development. Many research methods have been used during last years, in order to determine the genetic complexity of SCZ. A better understanding of the nature of risk genes would lead to a better comprehend of the causes of SCZ, resulting in developing more advanced diagnosis and treatment strategies [15].

One underlying topic of Paul Tooney's study was to link the gene changes with the biological dysfunctions found in the brain. Indeed, in the late ' $90 \mathrm{~s}$, a lot of researchers headed towards gene expression's microarray analysis, in an attempt to understand which genes caused a modification in brain's structure, when talking about SCZ [16], therefore, discovering the biological pathways which could be affected. The presence of thousands of gene fragments in a one single test permit to detect the changes of gene expression, into a significant fraction of the entire genome. The linear arrays of molecules are restrained in discreet locations, on an inert surface, which enables simultaneous analyses. Moreover, the microarray technology is frequently used for it is not only easy to implement, but it also is greatly controlled. Microarray is a glass slide, its dimension being comparable to a stamp, which contains thousands or hundreds of spots. Furthermore, each spot includes a synthetic deoxyribonucleic acid (DNA) strand, having a known sequence. One microarray consists of a specific gene portion (partially) and it is designed by placing a known DNA sequence. Thus, such studies show that a large number of genes is changed in the brain of subjects suffering from SCZ [17], but what causes this particular issue was not yet known.

The central dogma of the gene regulation, according to which the DNA codes for the mRNA are translated in proteins, was caused by the discovery of a new gene regulation mechanism, which encodes proteins through RNA species which do not encode, including microRNA (miRNA) [18]. mRNA is a RNA molecule, whose role is to copy the genetic information of one DNA strand, this process being called transcription. Moreover, mRNA is singled-stranded, having a variable length, depending both on the length of the gene (DNA) which it had transcripted, and the size of carried genetic message. It is associated with the ribosomes from the cell cytoplasm, at which level the sequence of amino acids, found in the polypeptide chain, dictates. After the RNA molecule fulfills its messenger role, it becomes subject to enzymatic hydrolysis and depolymerization. One single miRNA could link and affect hundreds of mRNA transcriptions; therefore, it could be explained why there are so many deranged genes found in the brain, when taking into account SCZ. Further studies, conducted on the postmortem brain of deceased persons suffering from SCZ, identified significant change of the miRNA expression [19]. The likely concern of miRNA, mandatory for understanding SCZ at the molecular level, has been pointed out by the Schizophrenia Working Group of the $P G C$ on a study focusing the entire genome, using a sample of 36989 disease cases and a sample of 113075 control cases. They discovered the link between SCZ and rs 1625579 genetic variation, located in the intron which encodes microRNA-137 (miR-137) [20]. On this account, based because hundreds of potential targets can be reached by miRNA, the task is to identify what is the relevant target of miR-137 involved in SCZ?

The calculation methods could pinpoint the potential targets associated to a specific miRNA, based on sequence of purinic base, which is used to usually link the three prime untranslated region (3'-UTR) to the mRNA target [21]. To establish which targets are relevant for SCZ and worth of further inquiries, Wu et al. [22] looked up in a study of Christian et al. [23], in order to identify SCZrelated genes, consisting of the target sequence for miR137. For instance, ephrin B2 (EFNB2) is that kind of gene, which was discovered as being linked to SCZ and miR137 should of target it. $\mathrm{Wu}$ et al. have used luciferase reporter analyses [human telomerase reverse transcriptase (hTERT)], for not only biologically showing that miR-137 targets 3'-UTR of EFNB2, but also exhibiting that the minor allele version ( $r 5550067317 \mathrm{C}$ ) found on this site has disturbed this interaction. Once the interaction was performed, the effects on the post-transcriptional levels of mRNA or proteins directly produced by miR-137 were sought. Using a neuroblastoma cell line, Wu et al. demonstrated reduced levels of endogenous EFNB2 protein by miR-137 without altering mRNA. Thus, it eliminates the used mechanism of miR-137, in order to influence the functional roles of EFNB2.

\section{ㅁ Practical implications}

Moreover, there is an intense interest in using information found in genes associated with SCZ because they can be considered as biomarkers that help in diagnosis. When we talk about SCZ, the changes in the genetic expression in the blood can be transposed at the brain level and as a result, in vivo studies also focus on blood studies [24]. A 2013 study correlated the cognitive deficits of a subtype of SCZ patients with a combination of severe negative symptoms and a variant of the MIR137 gene [25]. Thus, Wu et al. demonstrated high levels of miR-137 in patients with SCZ. In this way, it has been added to the diagnostic value in distinguishing SCZ patients from control cases sample. Based on the previously performed studies by $\mathrm{Wu}$ et al., it reveals that one subset of patients diagnosed with SCZ have a larger MIR137 gene expression, the fundamental addressed issue being the cognitive state of these particular schizophrenic individuals. 
The construction evidence suggests that miRNAs, specifically miR-137, can be seen as a biomarker because is involved in the development of SCZ. Additional efforts will determine their effectiveness in understanding the causes of SCZ, if they could be used for early diagnosis of SCZ. Moreover, they could give information on how current treatment options for SCZ may be improved.

Gershon et al. [26] is given a reference to the progress made on the human genetic map and on the genetic analysis of the link between complex inherited traits and major psychosis. On this regard, for chromosome 6 in SCZ and chromosomes 18 and 21 in bipolar affective disorder, there are relations of connection in more sets of independent data. These are low effect genes, finest being detected using methods of connection with relatively affected pair. The association with the candidate genes is an alternative strategy for discovering sensitivity genes related to these diseases, but compelling associations are still insufficiently established. Advanced methods of clinical and laboratory investigation are further developing. Moreover, it has been recently proposed testing each gene found in the human genome, in order to find associations related to the disease [27]. This task would require further progress in characterizing the genome and automatic widespread genotyping. The greatest sampling pedigree method for common diseases studies, regardless of linking nor associations, is still not established. A hybrid strategy of endophenotype could combine genetic link, clinical association and pathophysiological studies. Furthermore, as the molecular investigation methods are progressing, both the identification of the disease's susceptible mutations and their pathophysiological delimitation roles could be followed.

Furthermore, Pers et al. [28] have highlighted over 100 genetic loci associated with SCZ. The prioritization of genes and the analysis of transmission pathways have been made using published data implicating a large number of genes and gene sets. The gene complex human leukocyte antigen (HLA) locus has been found to be directly associated to SCZ. Using an evidence-based medicine database approach, there have been featured some gene characteristics found in loci related to SCZ: $(i)$ they are well expressed in cortical areas; (ii) they are rich in synaptic transmission ways, involving ion channels; (iii) they contain 62 genes which are functionally interlinked.

They validated the priority gene relevance, showing that they are enriched for both rare variants of disruption and de novo variants found in the sequencing SCZ studies (proportion rate 1.67, $p=0.039$ ). Genes which encode postsynaptic density (PSD) proteomics are enriched (proportion rate $4.56, p=5 \times 10^{-4}$; proportion rate $2.6, p=0.049$ ).

A meta-analysis conducted by Asarnow \& Forsyth [29] revealed that childhood onset SCZ correlates with familial transmission, precisely monozygotic twins, due to the higher heritability. Moreover, Schwab \& Wildenauer [30] further support the previously mentioned metaanalysis, by mentioning the $7 \%$ risk rate of $\mathrm{SCZ}$ for offspring having one parent diagnosed, compared to $0.86 \%$ having neither of the parents being diagnosed with a major psychiatric disorder. Copy number variations of genomes cannot be considered a risk predictor for SCZ.
Poletti \& Raballo [31], based on the SCZ PRS (s-PRS), concluded that SCZ is represented by a sum of dynamic phenotypic expressions found from the range of early ages to late adolescence. To this regard, it is revealed that anxiety (age 4-6); social difficulties (age 4-6); depression liability (age 7-9); attention deficit hyperactivity disorder (ADHD) and obsessive-compulsive disorder (OCD) (age 10-15), among other disorders and symptoms, lead to more specific SCZ spectrum phenotypes in late adolescence.

Bertram's meta-analysis [32] depicts more than 20 genes which are involved in SCZ symptoms, such examples being: AKT serine/threonine kinase 1 (AKT1) (all ethnicities); dopamine receptor D2 (DRD2) (Caucasian); methylenetetrahydrofolate reductase (MTHFR) (all ethnicities); reelin $(R E L N)$ (Caucasians); tumor protein p53 (TP53) (all ethnicities); glutamate ionotropic receptor $N$ methyl-D-aspartate (NMDA) type subunit 2B (GRIN2B) (all ethnicities). These results are taken into account in studies to come.

Sainz et al. [33] revealed that patients diagnosed with SCZ show an alteration of genes expression that are involved in reactions of wounding, acute inflammation. Moreover, they point out eight genes associated to SCZ: glutamate ionotropic receptor kainate type subunit 3 (GRIK3), lipoprotein lipase ( $L P L), \mathrm{S} 100$ calcium-binding protein B $(S 100 B)$, synuclein alpha $(S N C A)$, synapsin 2 (SYN2), tubulin beta 2A class IIa (TUBB2A), seleniumbinding protein 1 (SELENBP1), CUB and Sushi multiple domains 1 (CSMD1).

Jordan showed the fact that genetics, especially the expression of genes, is more prone to explain and detect SCZ. Therefore, $P G C$ revealed 108 viable schizophrenic loci, found in the human genome, each containing one or more genes, e.g., the DRD2 gene, which is responsible for the dopamine receptors [34].

$\mathrm{Xu}$ et al. concluded that SCZ-related loci genes found near human accelerated regions (HARs) regions (in humans) are also present in nonhuman primates, namely pHARs [35]. Moreover, pHARs-associated SCZ genes are found in more central positions, thus causing great impact for the genetic architecture of SCZ. In a study on Iranian population represented by 360 individuals, SCZ risk is given by three genotypes found in proline dehydrogenase 1 $(P R O D H)$ gene, namely: $757 T T, 1766 G G$, and $1852 A A$ $[25,36]$.

Tooney's review shows that miRNAs along with MIR137 gene could play a major role in developing SCZ [15]. Meaning, these genes could be used as biomarkers in diagnosing early SCZ in individuals. Furthermore, Pers et al. revealed that by prioritizing 62 genes [focusing GRIN2A and regulating synaptic membrane exocytosis 1 (RIMS1) genes - disruptive variants in schizophrenic cases] and 104 reconstituted gene sets for SCZ could lead to an early diagnosis [28].

Vassos et al. revealed that in the case of FEP patients, PRSs justifies a significant amount of variance (9.2\%) of SCZ for Europeans, rather than for African ancestors. Moreover, in the current case study, after FEP, 57\% of the individuals were diagnosed with SCZ, being highly susceptible to develop it later in life. Despite all this, PRS cannot discriminate between SCZ and other psychotic disorders [14]. 
Gonçalves et al. conducted a study which focused variants in nuclear-encoded mitochondrial genes that may raise awareness regarding SCZ. Results showed that the following mitochondrial genes are related to SCZ genes, namely: mitochondrial genes - DnaJ heat shock protein family 40 (Hsp40) member C19 (DNAJC19), heat shock protein 70 (Hsp70) family A member 9 (HSPA9) and propionyl-coenzyme A (CoA) carboxylase subunit beta $(P C C B)$ with adenosine triphosphatase (ATPase) sarcoplasmic/endoplasmic reticulum calcium transporting 2 (ATP2A2) (calcium signaling), contactin 4 (CNTN4) (neuronal network formation and plasticity) and fragile $\mathrm{X}$ mental retardation syndrome-related protein 1 (FXR1) (neurodevelopment) - SCZ genes [8]. However, Wnt family member $7 \mathrm{~A}$ ( $W N T 7 A)$ gene, being responsible for modulating both the synaptic vesicle cycle, as well as the synaptic transmission in hippocampal neurons, does not raise awareness towards SCZ [37].

An important aspect has been pointed out following the concerned analyses: The modern studies do not rely on the a priori selection of the genes and the sets of candidate genes, but equally deal with each set of genes and the genes in the associated loci. It is important to validate the relevance of the prioritized genes using this approach, reproducing data of exome sequencing and proteomic data of PSD.

The works researched from these perspectives contain some main specifications. Using strict criteria of significance, they involve numerous sets of genes and genes. The research particularly shows that the associated genes from loci of SCZ get rich for the sets of reconstructed genes related to the biological processes. It can be noticed from the studies carried on mice phenotypes: the dendritic development of the spinal column, calcium, glutamate and the signaling of the neuronal growth factor or some not clear processes as, e.g., the diacylglycerol kinase (DGK) activity [DGK iota (DGKI), DGK zeta (DGKZ) and phosphatidylinositol transfer protein membrane associated 2 (PITPNM2)]. In this way, the current studies offer additional evidence for the PSD and the customizations of the dendritic arborization in SCZ. Four sets of genes are significant from the viewpoint of this hypothesis: PSD, the postsynaptic layer, the dendritic spinal column, the axon part. In spite of this, no indication has been found for the sets of genes related to the methylation of histone $\mathrm{H} 3$ on lysine 4 (H3K4). Currently, the relationship between the immune system and SCZ is no longer valid (contrary to previous studies), although many of the genes related to immunity are situated in regions of $H L A$ imbalance; for this reason, data-driven expression-prioritized integration for complex traits (DEPICT) skips the $H L A$ location in the analysis. Is been validated that the $H L A$ locus is strongly associated with the SCZ.

The genes expressed in the adolescence period and in the maturity, the ages when SCZ is usually diagnosed, could represent more attractive medicinal aims than the development genes acting antenatal. The probable causal genes (GWAS) with loci involved in SCZ show a higher expression during the postnatal stages as compared to the prenatal ones. Similarly, Purcell et al. demonstrated that genes associated with SCZ are expressed postnatally rather than prenatal development (in the hippocampus and dorso- lateral prefrontal cortex regions) [38]. Furthermore, $P G C$ has shown recently using the expression data of the BrainSpan micro-tables that the expression of the genes involved in the immunological and neuronal pathways associated with the SCZ grew in the childhood and was completely present in adolescence.

\section{a Conclusions}

Within some systematic bioinformatic approaches, containing both results of the candidate genes and the ones of the GWAS analyses, the researchers will emphasize the numerous discoveries of the genetic associations that follow. Such an approach implies the SzGene database, which is now available highlighting a series of promising loci in SCZ, discovered by means of a systematic metaanalysis. SzGene does not explicitly intend to offer the last piece from the variant which the research is trying to solve in the genetic epidemiological domain. They rather try to offer an instrument which could help the researchers from several disciplines to decide which piece of the puzzle they are trying next. In the best case, this will also contribute to the accentuating the general image of the genetic forces determining the predisposition to $\mathrm{SCZ}$ and the pathogenesis of this disease. In the end, it is only the combined efforts of genetic, genomic, proteomic and the clinical disciplines that will give birth to new aims of diagnosis and treatment, which we hope that millions of patients suffering from this disabling disorder will benefit from in the not too distant future. Several advances in the intersected domain of SCZ disorder and genetics have been documented in recent literature, the focus being on an early diagnose of SCZ, based on specific genes. Further research on this topic is definitely needed. Correlations between the macroscopic findings, neural pathways, genetics and prenatal and postnatal, including adolescence findings will help improving the quality of life of patients with SCZ, in order to achieve a better integration in social life decreasing in this way the treatment and maintenance treatment costs. All together combined with documented evaluation of effectiveness of the treatment [39], using various investigation methods, included but not limited by macroscopic findings (under MRI environment), functional findings (fMRI), psychiatric/ psychological batteries and social enquiries, in order to have a more adequate vision of the quality of life and social integration of the patient, for the battery fight with SCZ.

\section{Conflict of interests}

The authors declare that they have no conflict of interests.

\section{References}

[1] Kaiser S, Lyne J, Agartz I, Clarke M, Mørch-Johnsen L, Faerden A. Individual negative symptoms and domains relevance for assessment, pathomechanisms and treatment. Schizophr Res, 2017, 186:39-45. https://doi.org/10.1016/j. schres.2016.07.013 PMID: 27453425

[2] Feldman R, Bailey RA, Muller J, Le J, Dirani R. Cost of schizophrenia in the Medicare program. Popul Health Manag, 2014, 17(3):190-196. https://doi.org/10.1089/pop.2013.0062 PMID: 24156665

[3] Gerlinger G, Hauser M, De Hert M, Lacluyse K, Wampers M, Correll CU. Personal stigma in schizophrenia spectrum disorders: a systematic review of prevalence rates, correlates, 
impact and interventions. World Psychiatry, 2013, 12(2):155164. https://doi.org/10.1002/wps.20040 PMID: 23737425 PMCID: PMC3683268

[4] Ladea M, Szöke A, Bran M, Baudin G, Slavu R, Pirlog MC, Briciu V, Udristoiu I, Schürhoff F, Ferchiou A. Schizotypal Personality Questionnaire-Brief: effect of invalid responding on factor structure analysis and scores of schizotypy. Encephale, 2020, 46(1):7-12. https://doi.org/10.1016/j.encep.2019.06.004 PMID: 31542212

[5] McGrath J, Saha S, Chant D, Welham J. Schizophrenia: a concise overview of incidence, prevalence, and mortality Epidemiol Rev, 2008, 30(1):67-76. https://doi.org/10.1093/epi $\mathrm{rev} / \mathrm{mxn} 001$ PMID: 18480098

[6] Thompson PM, Jahanshad N, Ching CRK, Salminen LE, Thomopoulos SI, Bright J, Baune BT, Bertolín S, Bralten J, Bruin WB, Bülow R, Chen J, Chye Y, Dannlowski U, de Kovel CGF, Donohoe G, Eyler LT, Faraone SV, Favre P, Filippi CA, Frodl T, Garijo D, Gil Y, Grabe HJ, Grasby KL, Hajek T, Han LKM, Hatton SN, Hilbert K, Ho TC, Holleran L, Homuth G, Hosten N, Houenou J, Ivanov I, Jia T, Kelly S, Klein M, Kwon JS, Laansma MA, Leerssen J, Lueken U, Nunes A, Neill JO, Opel N, Piras F, Piras F, Postema MC Pozzi E, Shatokhina N, Soriano-Mas C, Spalletta G, Sun D, Teumer A, Tilot AK, Tozzi L, van der Merwe C, Van Someren EJW, van Wingen GA, Völzke H, Walton E, Wang L, Winkler AM, Wittfeld K, Wright MJ, Yun JY, Zhang G, ZhangJames Y, Adhikari BM, Agartz I, Aghajani M, Aleman A, Althoff RR, Altmann A, Andreassen OA, Baron DA, BartnikOlson BL, Marie Bas-Hoogendam J, Baskin-Sommers AR, Bearden CE, Berner LA, Boedhoe PSW, Brouwer RM Buitelaar JK, Caeyenberghs K, Cecil CAM, Cohen RA, Cole JH, Conrod PJ, De Brito SA, de Zwarte SMC, Dennis EL, Desrivieres S, Dima D, Ehrlich S, Esopenko C, Fairchild G, Fisher SE, Fouche JP, Francks C, Frangou S, Franke B, Garavan HP, Glahn DC, Groenewold NA, Gurholt TP, Gutman BA, Hahn T, Harding IH, Hernaus D, Hibar DP Hillary FG, Hoogman M, Hulshoff Pol HE, Jalbrzikowski M, Karkashadze GA, Klapwijk ET, Knickmeyer RC, Kochunov P, Koerte IK, Kong XZ, Liew SL, Lin AP, Logue MW, Luders E, Macciardi F, Mackey S, Mayer AR, McDonald CR, McMahon AB, Medland SE, Modinos G, Morey RA, Mueller SC, Mukherjee P, Namazova-Baranova L, Nir TM, Olsen A, Paschou P, Pine DS, Pizzagalli F, Rentería ME, Rohrer JD, Sämann PG, Schmaal L, Schumann G, Shiroishi MS, Sisodiya SM, Smit DJ, Sønderby IE, Stein DJ, Stein JL, Tahmasian M, Tate DF, Turner JA, van den Heuvel OA, van der Wee NJ, van der Werf YD, van Erp TGM, van Haren NEM, van Rooij D, van Velzen LS, Veer IM, Veltman DJ, Villalon-Reina JE, Walter $H$, Whelan CD, Wilde EA, Zarei M, Zelman V; ENIGMA Consortium. ENIGMA and global neuroscience: a decade of large-scale studies of the brain in health and disease across more than 40 countries. Transl Psychiatry, 2020, 10(1):100. https://doi.org/10.1038/s41398-020-0705-1 PMID: 32198361 PMCID: PMC7083923

[7] Abi-Dargham A, Mawlawi O, Lombardo I, Gil R, Martinez D, Huang Y, Hwang DR, Keilp J, Kochan L, Van Heertum R, Gorman JM, Laruelle M. Prefrontal dopamine D1 receptors and working memory in schizophrenia. J Neurosci, 2002, 22(9): 3708-3719. https://doi.org/10.1523/JNEUROSCI.22-09-03708. 2002 PMID: 11978847 PMCID: PMC6758376

[8] Gonçalves VF, Cappi C, Hagen CM, Sequeira A, Vawter MP, Derkach A, Zai CC, Hedley PL, Bybjerg-Grauholm J, Pouget JG, Cuperfain AB, Sullivan PF, Christiansen M, Kennedy JL, Sun L. A comprehensive analysis of nuclear-encoded mitochondrial genes in schizophrenia. Biol Psychiatry, 2018, 83(9):780-789. https://doi.org/10.1016/..biopsych.2018.02.1175 PMID: 29628042 PMCID: PMC7168759

[9] Yasuda Y, Okada N, Nemoto K, Fukunaga M, Yamamori H, Ohi K, Koshiyama D, Kudo N, Shiino T, Morita S, Morita K, Azechi H, Fujimoto M, Miura K, Watanabe $\mathrm{Y}$, Kasai K, Hashimoto R. Brain morphological and functional features in cognitive subgroups of schizophrenia. Psychiatry Clin Neurosci, 2020, 74(3):191-203. https://doi.org/10.1111/pcn.12963 PMID: 31793131 PMCID: PMC7065166

[10] Raabe FJ, Slapakova L, Rossner MJ, Cantuti-Castelvetri L, Simons M, Falkai PG, Schmitt A. Oligodendrocytes as a new therapeutic target in schizophrenia: from histopathological findings to neuron-oligodendrocyte interaction. Cells, 2019, 8(12):1496. https://doi.org/10.3390/cells8121496 PMID: 31771166 PMCID: PMC6952785

[11] Kaar SJ, Angelescu I, Marques TR, Howes OD. Pre-frontal parvalbumin interneurons in schizophrenia: a meta-analysis of post-mortem studies. J Neural Transm (Vienna), 2019, 126(12):1637-1651. https://doi.org/10.1007/s00702-019-02080-2 PMID: 31529297 PMCID: PMC6856257

[12] Duchatel RJ, Shannon Weickert C, Tooney PA. White matter neuron biology and neuropathology in schizophrenia. NPJ Schizophr, 2019, 5(1):10. https://doi.org/10.1038/s41537-0190078-8 PMID: 31285426 PMCID: PMC6614474

[13] Hjelm BE, Rollins B, Mamdani F, Lauterborn JC, Kirov G, Lynch G, Gall CM, Sequeira A, Vawter MP. Evidence of mitochondrial dysfunction within the complex genetic etiology of schizophrenia. Mol Neuropsychiatry, 2015, 1(4):201-219. https://doi.org/10.1159/000441252 PMID: 26550561 PMCID: PMC4635522

[14] Vassos E, Di Forti M, Coleman J, lyegbe C, Prata D, Euesden J, O'Reilly P, Curtis C, Kolliakou A, Patel H, Newhouse S, Traylor M, Ajnakina O, Mondelli V, Marques TR, GardnerSood P, Aitchison KJ, Powell J, Atakan Z, Greenwood KE, Smith S, Ismail K, Pariante C, Gaughran F, Dazzan P, Markus HS, David AS, Lewis CM, Murray RM, Breen G. An examination of polygenic score risk prediction in individuals with first-episode psychosis. Biol Psychiatry, 2017, 81(6):470477. https://doi.org/10.1016/j.biopsych.2016.06.028 PMID: 27765268

[15] Tooney PA. Attention: schizophrenia risk gene product miR137 now targeting EFNB2. EBioMedicine, 2016, 12:10-11. https://doi.org/10.1016/j.ebiom.2016.10.004 PMID: 27733313 PMCID: PMC5078619

[16] Mirnics K, Middleton FA, Marquez A, Lewis DA, Levitt P. Molecular characterization of schizophrenia viewed by microarray analysis of gene expression in prefrontal cortex. Neuron, 2000, 28(1):53-67. https://doi.org/10.1016/s0896-6273(00)00 085-4 PMID: 11086983

[17] Bowden NA, Scott RJ, Tooney PA. Altered gene expression in the superior temporal gyrus in schizophrenia. BMC Genomics, 2008, 9(1):199. https://doi.org/10.1186/1471-2164-9-199 PMID: 18445270 PMCID: PMC2386488

[18] Lee RC, Feinbaum RL, Ambros V. The C. elegans heterochronic gene lin-4 encodes small RNAs with antisense complementarity to lin-14. Cell, 1993, 75(5):843-854. https://doi.org/10.1016/ 0092-8674(93)90529-y PMID: 8252621

[19] Beveridge NJ, Tooney PA, Carroll AP, Gardiner E, Bowden N, Scott RJ, Tran N, Dedova I, Cairns MJ. Dysregulation of miRNA $181 \mathrm{~b}$ in the temporal cortex in schizophrenia. Hum Mol Genet, 2008, 17(8):1156-1168. https://doi.org/10.1093/ hmg/ddn005 PMID: 18184693

[20] Schizophrenia Working Group of the Psychiatric Genomics Consortium. Biological insights from 108 schizophreniaassociated genetic loci. Nature, 2014, 511(7510):421-427. https://doi.org/10.1038/nature13595 PMID: 25056061 PMCID: PMC4112379

[21] Sidore C, Busonero F, Maschio A, Porcu E, Naitza S, Zoledziewska M, Mulas A, Pistis G, Steri M, Danjou F, Kwong A, Ortega Del Vecchyo VD, Chiang CWK, BraggGresham J, Pitzalis M, Nagaraja R, Tarrier B, Brennan C, Uzzau S, Fuchsberger C, Atzeni R, Reinier F, Berutti R, Huang J, Timpson NJ, Toniolo D, Gasparini P, Malerba G, Dedoussis G, Zeggini E, Soranzo N, Jones C, Lyons R, Angius A, Kang HM, Novembre J, Sanna S, Schlessinger D, Cucca F, Abecasis GR. Genome sequencing elucidates Sardinian genetic architecture and augments association analyses for lipid and blood inflammatory markers. Nat Genet, 2015, 47(11):1272-1281. https://doi.org/10.1038/ng.3368 PMID: 26366554 PMCID: PMC4627508

[22] Wu TP, Wang T, Seetin MG, Lai Y, Zhu S, Lin K, Liu Y, Byrum SD, Mackintosh SG, Zhong M, Tackett A, Wang G, Hon LS, Fang G, Swenberg JA, Xiao AZ. DNA methylation on $\mathrm{N}^{6}$-adenine in mammalian embryonic stem cells. Nature, 2016, 532(7599):329-333. https://doi.org/10.1038/nature17 640 PMID: 27027282 PMCID: PMC4977844

[23] Christian M, Cermak T, Doyle EL, Schmidt C, Zhang F, Hummel A, Bogdanove AJ, Voytas DF. Targeting DNA doublestrand breaks with TAL effector nucleases. Genetics, 2010, 
186(2):757-761. https://doi.org/10.1534/genetics.110.120717 PMID: 20660643 PMCID: PMC2942870

[24] Sullivan PF. The genetics of schizophrenia. PLoS Med, 2005, 2(7):e212. https://doi.org/10.1371/journal.pmed.0020212 PMID: 16033310 PMCID: PMC1181880

[25] Green RC, Berg JS, Grody WW, Kalia SS, Korf BR, Martin CL, McGuire AL, Nussbaum RL, O'Daniel JM, Ormond KE, Rehm HL, Watson MS, Williams MS, Biesecker LG; American College of Medical Genetics and Genomics. ACMG recommendations for reporting of incidental findings in clinical exome and genome sequencing. Genet Med, 2013, 15(7):565-574. https://doi. org/10.1038/gim.2013.73 PMID: 23788249 PMCID: PMC 3727274

[26] Gershon ES, Badner JA, Goldin LR, Sanders AR, Cravchik A Detera-Wadleigh SD. Closing in on genes for manic-depressive illness and schizophrenia. Neuropsychopharmacology, 1998, 18(4):233-242. https://doi.org/10.1016/S0893-133X(97)00145-0 PMID: 9509491

[27] Risch N, Merikangas K. The future of genetic studies of complex human diseases. Science, 1996, 273(5281):1516-1517. https:// doi.org/10.1126/science.273.5281.1516 PMID: 8801636

[28] Pers TH, Timshel P, Ripke S, Lent S, Sullivan PF, O'Donovan MC, Franke L, Hirschhorn JN; Schizophrenia Working Group of the Psychiatric Genomics Consortium. Comprehensive analysis of schizophrenia-associated loci highlights ion channel pathways and biologically plausible candidate causal genes. Hum Mol Genet, 2016, 25(6):12471254. https://doi.org/10.1093/hmg/ddw007 PMID: 26755824 PMCID: PMC4764200

[29] Asarnow RF, Forsyth JK. Genetics of childhood-onset schizophrenia. Child Adolesc Psychiatr Clin N Am, 2013, 22(4):675687. https://doi.org/10.1016/j.chc.2013.06.004 PMID: 24012080 PMCID: PMC4364758

[30] Schwab SG, Wildenauer DB. Genetics of psychiatric disorders in the GWAS era: an update on schizophrenia. Eur Arch Psychiatry Clin Neurosci, 2013, 263(Suppl 2):S147-S154. https://doi.org/10.1007/s00406-013-0450-z PMID: 24071914

[31] Poletti M, Raballo A. Polygenic Risk Score and the (neuro) developmental ontogenesis of the schizophrenia spectrum vulnerability phenotypes. Schizophr Res, 2018, 202:389-390. https://doi.org/10.1016/.schres.2018.04.036 PMID: 29735200

[32] Bertram L. Genetic research in schizophrenia: new tools and future perspectives. Schizophr Bull, 2008, 34(5):806-812. https://doi.org/10.1093/schbul/sbn079 PMID: 18644854 PMCID: PMC2632466

[33] Sainz J, Mata I, Barrera J, Perez-Iglesias R, Varela I, Arranz MJ, Crespo-Facorro B. Inflammatory and immune response genes have significantly altered expression in schizophrenia. Mol Psychiatry, 2013, 18(10):1056-1057. https://doi.org/10.1038/ mp.2012.165 PMID: 23164819

[34] Jordan B. Les « genes » de la schizophrénie - chroniques génomiques ["Genes » for schizophrenia]. Med Sci (Paris), 2014, 30(10):922-924. https://doi.org/10.1051/medsci/2014 3010021 PMID: 25313623

[35] Xu K, Schadt EE, Pollard KS, Roussos P, Dudley JT. Genomic and network patterns of schizophrenia genetic variation in human evolutionary accelerated regions. Mol Biol Evol, 2015, 32(5):1148-1160. https://doi.org/10.1093/molbev/msv031 PMID: 25681384 PMCID: PMC4408416

[36] Ghasemvand F, Omidinia E, Salehi Z, Rahmanzadeh S. Relationship between polymorphisms in the proline dehydrogenase gene and schizophrenia risk. Genet Mol Res, 2015, 14(4):11681-11691. https://doi.org/10.4238/2015.October.2.1 PMID: 26436492

[37] Hu TM, Ping LY, Hsu SH, Tsai HY, Cheng MC. Mutation analysis of the WNT7A gene in patients with schizophrenia. Psychiatry Res, 2018, 265:246-248. https://doi.org/10.1016/ j.psychres.2018.04.057 PMID: 29763843

[38] Purcell S, Neale B, Todd-Brown K, Thomas L, Ferreira MAR, Bender D, Maller J, Sklar P, de Bakker PIW, Daly MJ, Sham PC. PLINK: a tool set for whole-genome association and population-based linkage analyses. Am J Hum Genet, 2007, 81(3):559-575. https://doi.org/10.1086/519795 PMID: 17701901 PMCID: PMC1950838

[39] Ladea M, Barbu CM, Juckel G. Treatment effectiveness in patients with schizophrenia as measured by the ASSESS battery - first longitudinal data. Psychiatr Danub, 2015, 27(4): 364-370. PMID: 26609648

\section{Corresponding author}

Simona Corina Trifu, Lecturer, PhD, Department of Neurosciences, Carol Davila University of Medicine and Pharmacy, 37 Dionisie Lupu Street, Sector 2, 020021 Bucharest, Romania; Phone +40731-581 100, Fax +4031-105 58 90, e-mail: simonatrifu@yahoo.com 